\title{
Professores do ensino fundamental e bem-estar subjetivo: uma explicação baseada em valores
}

\author{
Patrícia Nunes da Fonseca ${ }^{1}$ \\ Sandra Soura da Silva Chaves \\ Valdiney Veloso Gouveia
}

\begin{abstract}
Resumo
Este estudo teve como objetivo conhecer em que medida estão correlacionados os valores humanos e o bem-estar subjetivo dos professores do ensino fundamental do estado da Paraíba. Participaram 313 professores, que responderam o Questionário dos Valores Básicos, a Escala de Afetos Positivos e Negativos, a Escala de Vitalidade, o Questionário de Saúde Geral - QSG-12 e a Escala de Satisfação com a Vida e perguntas socioocupacionais. Dentre os resultados encontrados, destacam-se os valores normativos apresentando correlação direta com os afetos positivos $(\mathrm{r}=0,17, \mathrm{p}<0,01)$ e satisfação com a vida $(\mathrm{r}=0,12, \mathrm{p}<0,05)$ e correlacionando-se negativamente com depressão $(\mathrm{r}=-0,13, \mathrm{p}<0,05)$ e com a pontuação total do bem-estar $(\mathrm{r}=-0,18, \mathrm{p}<0,01)$. Os resultados podem ser melhor compreendidos a partir do contexto socioocupacional desses profissionais.
\end{abstract}

Palavras-chave: Bem-estar subjetivo; Valores; Saúde do trabalhador.

\section{Primary-school teachers' subjective well-being: an explanation based on value priorities}

\begin{abstract}
The objective of this study is to find out to what extent there is a relationship between the human values and the subjective well-being of primary-school teachers in the State of Paraíba. 313 teachers who answered the Basic Values Questionnaire, the Positive and Negative Affection Scale, the Vitality Scale, the General Health Questionnaire - QSG-12 (GHQ), the Life Satisfaction Scale together with some social-occupational questions took part in this research. Among the findings, the normative values stand out showing a direct correlation with the positive affections $(r=0,17, \mathrm{p}<0,01)$ and with life satisfaction $(\mathrm{r}=0,12, \mathrm{p}<0,05)$ as well as a negative correlation with depression $(\mathrm{r}=-0,13, \mathrm{p}<0,05)$ and with the total score concerning well-being $(\mathrm{r}=-0,18, \mathrm{p}<0,01)$. The results may be better understood taking into account the socio-occupational context of these professionals.

Keywords: Subjective well-being; Values; Worker health.
\end{abstract}

\section{Introdução}

O bem-estar subjetivo tem se tornado tema central nas diversas pesquisas do comportamento humano. Estudos têm discutido sua relação com a religião, a raça, o aborto (Russo \& Dabul, 1997), os traços de personalidade (Schmutte \& Ryff, 1997), o lócus de controle (Grob, Little, Wanner \& Wearing, 1996), etc., culminando numa amplitude de variáveis que possam estar explicando, ou tão-somente, influenciando esse estado subjetivo (Chaves, 2003).

No Brasil, há um aumento de estudos sobre o bem-estar subjetivo, (Chaves, 2003; Gusmão, 2004;
Tróccoli \& Salazar, 2003; Tróccoli, Salazar \& Vasconcelos, 2002) entretanto, nenhum desses tem focalizado o trabalho docente. Embora a inexistência de trabalho sobre esta temática seja uma realidade, percebe-se a sua necessidade ao se constatar que o ensino é uma atividade onde se observam diversos estressores psicossociais, os quais estão relacionados à natureza da profissão, ou tãosomente ao contexto político, social e institucional onde as atividades são exercidas (Carlotto, 2002).

No caso dos estressores, um fato que tem chamado a atenção é a síndrome de Bournout. Estudos têm enfocado que tal síndrome e sua relação com o trabalho docente evidenciam resultados que são considerados preocupantes no que diz respeito à saúde do trabalhador.

\footnotetext{
${ }^{1}$ Endereço para correspondência:

Av. Espírito Santo, 422 - Bairro dos Estados - 58030-110 - João Pessoa-PB

Tel. (083) 2243752

E-mail: patynfonseca@uol.com.br
} 
Buscando estudar a profissão dos professores sob o ponto de vista de uma perspectiva mais positiva da Psicologia, este trabalho é proposto na medida em que focaliza o bem-estar desses profissionais.

Nas publicações internacionais (Kasser \& Ryan, 1993, 1996; Oishi, Diener, Lucas \& Suh, 1999; Ryan \& Deci, 2001) ou nacionais (Chaves, 2003; Gusmão, 2004) observa-se que há uma tendência a se estudar o bemestar subjetivo relacionando-o aos valores humanos, o que evidencia a importância da relação entre tais construtos. No caso do presente estudo, esta relação antes citada, deve ser fundamentada a partir do contexto socioocupacional dos professores.

\section{O bem-estar subjetivo}

O bem-estar tem sido foco de interesse de estudiosos (Diener, 2000; Kasser \& Ryan, 1993, 1996; Lucas, Diener \& Suh, 1996; Ryan \& cols., 1999; Ryan \& Deci, 2000) da Psicologia na última década. Mais especificamente, a Psicologia Organizacional e do Trabalho tem lhe dado bastante atenção por ser um tema importante quando se pesquisa a saúde do trabalhador.

Danna e Griffin (1999) consideram o bem-estar como um conceito mais amplo do que a saúde por englobar os diversos aspectos da vida do indivíduo, como, a esfera social, familiar, do trabalho, etc. Já a saúde é percebida como um sub-componente do bem-estar, incluindo indicadores físicos e mentais, a saber, afeto, frustração, ansiedade e sintomatologia física.

A definição que fundamentará a presente pesquisa é a de Ryan e Deci (2001), sendo o bem-estar definido como um funcionamento e uma experiência psicológica adequados, não se tratando tão só de ausência de doença mental, mas sim de um estado de satisfação consigo mesmo e com o ambiente em sua volta.

Os estudos pontuam vários indicadores de bemestar subjetivo, o que caracteriza sua perspectiva multidimensional. Chaves (2003), estudando a relação entre o bem-estar subjetivo e os valores humanos na população geral do contexto paraibano, comprovou a adequação de um modelo multidimensional de bem-estar subjetivo, que abrange tanto aspectos cognitivos como afetivos. Nesse caso, utilizou-se tanto uma medida geral do bem-estar como também os diferentes indicadores que a conformam (afetos positivos, afetos negativos, ansiedade $\mathrm{e}$ depressão, satisfação com a vida e vitalidade). A presente pesquisa se propôs a utilizar esse modelo convergente, o que poderá ser verificado na descrição dos instrumentos considerados.

Segundo Danna e Griffin (1999), é impossível separar a vida pessoal do trabalhador e a vida no local de trabalho. O empregado passa cerca de um terço de seu tempo trabalhando e qualquer coisa que venha a acontecer em qualquer esfera da vida afeta diretamente a vida como um todo. A psicologia da saúde ocupacional tem merecido um local de destaque nos estudos da saúde do trabalhador por se preocupar com as condições de trabalho, bem como a prevenção de doenças (Sauter \& Hurrell Jr., 1999).

Os autores anteriormente citados apontam a necessidade de se aprofundar na temática sobre o bemestar e a saúde devido à crescente consciência que se tem das conseqüências para o trabalhador e para a empresa. Por exemplo, uma pessoa que não esteja saudável não pode ser produtiva ou tem uma diminuição de sua produtividade comprometendo também sua organização no trabalho.

Para se avaliar o bem-estar dos professores é necessário investigar o contexto de trabalho desses profissionais, uma vez que têm surgido novos modos de organizar o trabalho, bem como novas formas nas relações dos empregos, que trazem mudanças significativas a nível individual, nas firmas e nas sociedades como um todo (Rousseau, 1997). No atual contexto do mundo do trabalho, os professores da educação básica também têm enfrentado sérias e profundas transformações em seu contexto profissional, o que poderá ser melhor analisado em seguida.

\section{Contexto socioocupacional dos professores}

Nos últimos 30 anos, a formação dos professores tornou-se tema de debate na academia, especialmente após 1968, quando se deu a formação das faculdades ou centros de educação nas universidades brasileiras. A partir de 1990, observa-se um aumento no número de investigações sobre a profissão docente nas universidades e instituições de pesquisa no Brasil. Entretanto, apesar de todo esse investimento, os cursos de licenciatura, que habilitavam para o exercício dessa profissão, permaneciam sem alterações desde a década de 1930. Foi, portanto, a partir da Lei de Diretrizes e Bases da Educação Nacional - LDB - Lei n. ${ }^{\circ}$ 9.394/96 (Brasil, 1996), que se iniciaram discussões acerca da formação do docente no Brasil, em que os professores deveriam possuir o nível superior ou tão-somente estar cursando até o ano de 2006 (Melo, 1999).

Para cumprir tais exigências, universidades particulares implantaram um curso de Pedagogia em Regime Especial com o propósito de possibilitar aos educadores a formação superior em horário especial, no caso, aos sábados no intervalo das $7 \mathrm{~h} 30$ até às 12 horas e das $13 \mathrm{~h}$ até às $17 \mathrm{~h} 30$. Para atender a essa demanda, a estrutura desse curso especial foi fixada no mínimo em 2.800 horas, em que o professor (universitário) cursa disciplinas

Psico-USF, v. 11, n. 1, p. 45-52, jan./jun. 2006 
obrigatórias, optativas e complementares e ainda realiza estágio supervisionado e uma supervisão pedagógica continuada por um período de três anos. Além disso, o professor (universitário) incorpora as horas dedicadas à atividade docente como parte integrante da estrutura curricular. Ao final desse período, o professor sairá com sua formação de nível superior, enquadrando-se, portanto, nos moldes da Lei citada anteriormente.

Como pode ser observado, as exigências das políticas educacionais dos últimos anos têm trazido uma crescente gama de professores em busca de uma formação superior para que possam se manter no atual mercado de trabalho. Como assinala Mariano (2003), é importante considerar nas pesquisas, os impactos das políticas educacionais para as condições de trabalho desse profissional.

Como dito antes, sabendo-se que as mudanças ocorridas em uma esfera da vida afetam a pessoa como um todo, como se encontra a saúde e/ou bem-estar dos trabalhadores diante das transformações ocorridas no mundo do trabalho nos últimos tempos e até que ponto os valores humanos estariam influenciando o bem-estar desses profissionais? Essa é a pergunta inicial que permeia toda a problemática dessa pesquisa.

\section{Valores humanos}

O estudo dos valores humanos tem sido tema abordado por diferentes áreas do conhecimento, como Educação, Filosofia, Psicologia, Sociologia. Isto porque ele tem um papel relevante na orientação do comportamento humano, e mais, na organização das pessoas em sociedade (Rokeach, 1973).

Sendo assim, selecionou-se esta variável como explicativa do bem-estar subjetivo dos professores. Para este estudo, foi adotada a tipologia dos valores humanos básicos de Gouveia (2003). Essa tipologia, baseada na teoria da hierarquia das necessidades de Abraham Maslow, a qual pressupõe que: a) as necessidades humanas são universais; b) as necessidades são neutras ou positivas; c) organizam-se em função de uma hierarquia que varia das fisiológicas (comer, beber, ter relações sexuais), passando pelas de segurança (estabilidade, proteção, ordem), de amor e afiliação (receber e dar carinho, ter companheiros), cognitivas (desejo de conhecimento, entendimento, explicação e satisfação da curiosidade), estética (desejo de beleza, simetria e boa forma) até chegar à auto-realização (vontade de melhorar e ser auto-suficiente); d) o homem caminha em direção à auto-realização; e f) a pessoa é um todo organizado e integrado.

Entretanto, apesar de Gouveia (2003) ter como referência os pressupostos maslownianos sobre os tipos e a natureza das necessidades, não aceita a idéia de hierarquia destas. Para esse autor, os valores representariam as pré-condições para satisfazer as necessidades. Estas incluem: liberdade, igualdade, honestidade e disciplina nos grupos.

Desta forma, Gouveia (1998) define os valores básicos como

categorias de orientação desejáveis, que estão baseadas nas necessidades humanas e nas pré-condições para satisfarê-las, sendo adotadas por atores sociais $e$ podendo variar em sua magnitude e nos elementos que as constituem (p. 293).

A tipologia dos valores humanos básicos de Gouveia (2003) apresenta um conjunto de 24 valores básicos, organizados em três critérios de orientação (pessoal, central e social), cada um definido por duas funções psicossociais.

Valores Pessoais. Pessoas que assumem este critério de orientação costumam manter relações pessoais do tipo contratual, geralmente com objetivos proveitosos para si. As suas funções psicossociais podem ser assim classificadas: a) Experimentação (estimulação, emoção, sexual e prazer) que enfatiza o fato de descobrir e apreciar novos estímulos, enfrentar situações limites, além de buscar satisfação sexual. b) Realização (êxito, poder, prestigio, autodireção e privacidade) caracteriza-se pelo sentimento de ser importante e poderoso, ser uma pessoa com identidade e espaço próprio.

Valores Centrais. Esta expressão indica o caráter central desses valores. Representa um padrão de confluência dos valores, sugerindo condições mínimas para que exista convivência em sociedade. Classificam-se da seguinte forma no que diz respeito às suas funções psicossociais: a) Valores de Existência (sobrevivencia, saúde e estabilidade pessoal): expressa uma preocupação de garantir a própria existência orgânica com ênfase não na individualidade da pessoa, mas na sobrevivência em si; b) Valores Suprapessoais (justica social, conhecimento, beleza e maturidade): As pessoas que adotam esses valores procuram alcançar seus objetivos ou ideais independentemente do grupo afiliativo ou condição social. Indica alguém maduro, isto é, uma pessoa que não se limita a traços ou características específicas para iniciar uma relação ou proporcionar benefícios.

Valores Sociais. As pessoas que pautam por este critério de orientação o fazem em direção aos demais, comportando-se como alguém que gosta de ser considerado, que deseja ser aceito pelo grupo. No que diz respeito às suas funções psicossociais, podem ser divididos em: a) Valores Normativos (religiosidade, ordem social, tradição e obediência): aqui, as pessoas dão ênfase à 
vida social, à estabilidade grupal, além de respeitar os símbolos e padrões culturais que prevaleceram durante anos. b) Valores Interacionais (afetividade, apoio social, convivencia e honestidade): privilegiados por pessoas que baseiam seus interesses em se sentirem queridas, terem amizades verdadeiras e uma vida social ativa. A intimidade com os outros é fundamental para assegurar a própria felicidade.

Com base nesse referencial teórico, e como dito anteriormente, a presente pesquisa objetiva conhecer em que medida estão correlacionados os valores humanos e o bem-estar subjetivo dos professores do estado da Paraíba, uma vez que existe escassez de pesquisas na realidade brasileira acerca desta temática.

\section{Método}

\section{Delineamento e bipóteses}

Trata-se de um estudo correlacional. Baseandose nos referenciais teóricos discorridos previamente acerca do bem-estar subjetivo e dos valores humanos e nos objetivos mencionados, foram formuladas as seguintes hipóteses:

Hipótese 1 - Os valores normativos (tradição, obediência, religiosidade ordem social) se correlacionarão positivamente com os indicadores de bem-estar subjetivo, assim como com sua pontuação total;

Hipótese 2 - Os valores interacionais (afetividade, apoio social, convivência, honestidade) se correlacionarão positivamente com os indicadores de bem-estar subjetivo, assim como com sua pontuação total;

Hipótese 3 - Os valores de existência (sobrevivência, saúde, estabilidade pessoal) se correlacionarão positivamente com os indicadores de bem-estar subjetivo, assim como com sua pontuação total;

Hipótese 4 - Os valores de suprapessoal (justiça social, conhecimento, beleza, maturidade) se correlacionarão positivamente com os indicadores de bem-estar subjetivo, assim como com sua pontuação total;

Hipótese 5 - Os valores de experimentação (estimulação, emoção, sexual, prazer) se correlacionarão inversamente com os indicadores de bem-estar subjetivo, assim como com sua pontuação total;

Hipótese 6 - Os valores de realização (êxito, poder, prestígio, autodireção, privacidade) se correlacionarão inversamente com os indicadores de bem-estar subjetivo, assim como com sua pontuação total.

\section{Amostra}

Participaram deste estudo 313 professores do ensino fundamental de escolas públicas e privadas do estado da Paraíba, com idade variando entre 18 e 58 anos $(M=33,6 ; D P=9,09)$, sendo $91,4 \%$ do sexo feminino; $52,4 \%$ casadas e $47,9 \%$ da rede pública.

\section{Instrumentos}

Os participantes responderam um questionário constando de 6 partes:

Questionários dos Valores Básicos. Este instrumento foi elaborado inicialmente por Gouveia (1998). A versão utilizada compreende um conjunto de 24 valores (por exemplo, obediencia: cumprir seus deveres e obrigações do dia-a-dia; respeitar aos seus pais e aos mais velhos; emoção: desfrutar desafiando o perigo; buscar aventuras), respondidos numa escala com nove pontos. Primeiramente, o respondente deve indicar o grau de importância que cada um dos valores tem na sua vida, utilizando uma escala de resposta de sete pontos, com os seguintes extremos: $\mathbf{1}=$ Pouco Importante e $\mathbf{7}=$ Muito Importante. Em seguida, deve indicar o valor que considera o mais importante de todos enquanto um princípio-guia em sua vida, e depois indicar o valor que considera o menos importante de todos. Para estes dois valores serão atribuídos os escores 8 e 0 , respectivamente. Tais escores substituem os graus de importância previamente definidos para os valores correspondentes. Esta medida apresenta parâmetros psicométricos adequados para a população brasileira. Gouveia (2003) relata, por exemplo, que esta medida apresenta validade convergente com a que propõe S. H. Schwartz; ademais observou índices de bondade de ajuste aceitáveis para estrutura fatorial proposta: $\chi^{2} /$ g.l. $=2,67 ; G F I=0,91$; $A G F I=0,89$ e RMSE $A=0,05$.

Escala de Afetos Positivos e Negativos. Esta escala foi originalmente elaborada por Diener e Emmons (1984, citados por Reis, Sheldon, Gable, Roscoe \& Ryan, 2000) para avaliar a valência dos afetos.

Escala de Vitalidade. Este instrumento foi originalmente elaborado por Ryan e Frederick (1997). Esta medida avalia o grau em que o participante tem se sentido em termos de vigor físico, mental e alerta, nos últimos dias e seus parâmetros psicométricos têm se mostrado adequados em estudos recentes (Kasser \& Ahuvia, 2002; Kasser \& Ryan, 1993; Nix, Ryan, Manly \& Deci, 1999).

Questionário de Saúde Geral, QSG-12. Este instrumento compreende uma versão abreviada do Questionário de Saúde Geral de Goldberg, adaptado para o Brasil por Pasquali, Gouveia, Andriola, Miranda e Ramos (1994). O QSG-12, como seu nome sugere, compõe-se de 12 itens 
(por exemplo, tem se sentido pouco feliz e deprimido; tem perdido a confiança em si mesmo). Cada item é respondido em termos do quanto a pessoa tem experimentado os sintomas descritos, devendo sua resposta ser dada em uma escala de quatro pontos.

Escala de Satisfação com a Vida. Esta medida foi elaborada originalmente por Diener, Emmons, Larsen e Griffin (1985), tendo sido realizados estudos recentes que atestam a adequação dos seus parâmetros psicométricos (Pavot \& Diener, 1993).

Informações Socioocupacionais. Um conjunto de 18 perguntas foi formulado visando caracterizar a amostra, a exemplo de idade, sexo, tempo de serviço, instituição em que ensina, etc.

\section{Procedimento}

Inicialmente foram apresentados aos professores (univsersitários) o objetivo geral do estudo, garantindo o anonimato e o sigilo das respostas dos participantes. Posteriormente, foram convidados a responder voluntariamente o questionário. A aplicação ocorreu coletivamente em sala de aula, sendo enfatizado que as respostas deveriam ser dadas individualmente. O tempo médio para o preenchimento dos questionários foi de 25 minutos.

\section{Análise dos dados}

Foram efetuadas análises descritivas (média, desvio padrão, freqüência e porcentagem) a fim de caracterizar o grupo de respondentes, assim como correlações ( $r$ de Pearson).

\section{Resultados e discussão}

A presente pesquisa se centra principalmente em conhecer a correlação dos valores com o bem-estar subjetivo dos professores do estado da Paraíba. Deste modo, foram formuladas seis hipóteses, e os resultados dessas correlações são apresentados na Tabela 1, a seguir.

A primeira hipótese foi parcialmente corroborada. Como pode ser visto na Tabela 1 , a função psicossocial normativa apresentou correlação direta e significativa com os afetos positivos $(\mathrm{r}=0,17, \mathrm{p}<0,01)$ e satisfação com a vida $(\mathrm{r}=0,12, \mathrm{p}<0,05)$ e correlacionou negativamente com depressão $(\mathrm{r}=-0,13, \mathrm{p}<0,05)$ e com a pontuação total do bem-estar $(\mathrm{r}=-0,18, \mathrm{p}<0,01)$. Entre os seus valores específicos, tradição apresentou correlação positiva forte com afetos positivos $(\mathrm{r}=0,23, \mathrm{p}<0,001) \mathrm{e}$ correlação inversa, igualmente forte, com bem-estar $(\mathrm{r}=$ $-0,25, \mathrm{p}<0,001)$. Os indivíduos que priorizam os valores normativos (Gouveia, 2003) dão ênfase à vida social e à estabilidade grupal. Neste caso, tais resultados apontam que, embora os professores pareçam gozar de afetos positivos e satisfação com a vida, contrariamente, pontuaram alto em depressão e no bem-estar geral. Isto pode estar sendo refletido, por um lado, aos aspectos relacionados à síndrome de burnout, tão comum na profissão (Carlotto, 2002) e, por outro, ao contexto profissional em que os professores estão submetidos após a aprovação da Lei de Diretrizes e Bases da Educação - LDB - Lei n. ${ }^{\circ}$ 9.394/96 (Brasil, 1996), a qual exige a formação superior até 2006. Como já comentado antes, essa exigência pode estar contribuindo para um deterioro do bem-estar, diante da sobrecarga de atividades profissionais, além de uma dedicação acadêmica intensiva, costumeiramente destinado aos finais de semana.

A segunda hipótese não foi corroborada. A função psicossocial interacional se correlacionou negativamente com depressão ( $\mathrm{r}=-0,12, \mathrm{p}<0,05)$. As correlações mais fortes foram encontradas no valor convivência, sendo direta nos afetos positivos ( $\mathrm{r}=0,22, \mathrm{p}<0,001)$ e negativa para o bem-estar geral $(\mathrm{r}=-0,21, \mathrm{p}<0,001)$. Por fazer parte do critério de orientação valorativa social, as pessoas que buscam se guiar pelos valores interacionais enfatizam a complacência, isto é, a intimidade com os outros passa a ser um aspecto importante para assegurar a própria felicidade. Pelo fato dos professores terem uma atividade profissional que mantém o convívio com as pessoas, no caso específico da presente pesquisa, com crianças, esperava-se, pois, que pontuassem significativamente no bem-estar. Entretanto, apesar de pontuarem alto no valor convivência, especificamente nos afetos positivos, no geral apontam um deterioro no bemestar geral. Este resultado parece revelar que apesar do trabalho proporcionar oportunidade para interagir, conviver com as pessoas, a falta de tempo nos finais de semana os impede de ter uma vida social ativa, fora do ambiente de trabalho onde possam compartilhar suas idéias e perspectivas. Sem isso, os professores aparentemente vivenciam um estado de tristeza, desânimo, solidão e melancolia, sintomatologia típica da depressão (Ebert, Loosen \& Nurcombe, 2002).

A terceira e a quarta hipóteses não foram corroboradas, pois os valores da função de existência, assim como os suprapessoais não apresentaram correlação com os indicadores do bem-estar geral.

Este resultado merece destaque, uma vez que as funções de existência e a suprapessoais compõem os valores centrais, os quais priorizam tanto os aspectos sociais quanto os pessoais, sendo, portanto, compatíveis. No caso do presente estudo, esperava-se que os professores, por estarem em busca de uma formação superior, pontuassem alto nos valores de existência, 
Tabela 1 - Correlações entre os valores humanos básicos e os indicadores de bem-estar subjetivo

\begin{tabular}{|c|c|c|c|c|c|c|c|}
\hline Valores & I & II & III & IV & $\mathrm{V}$ & VI & Total \\
\hline Normativos & $0,17 * *$ & $-0,08$ & $-0,13^{*}$ & $-0,06$ & 0,07 & $0,12^{*}$ & $-0,18^{* *}$ \\
\hline Tradição & $0,23^{* * *}$ & $-0,13^{*}$ & $-0,16 * *$ & $-0,15^{* *}$ & 0,10 & $0,17 * *$ & $0,25 * * *$ \\
\hline Obediência & $0,18^{* *}$ & $-0,06$ & $-0,11$ & $-0,05$ & 0,06 & 0,04 & $-0,15^{* *}$ \\
\hline Religiosidade & 0,03 & $-0,05$ & $-0,04$ & 0,01 & $-0,03$ & $-0,07$ & $-0,03$ \\
\hline Ordem social & $-0,06$ & 0,07 & 0,02 & 0,09 & 0,02 & $-0,05$ & 0,04 \\
\hline Interacional & 0,09 & $-0,02$ & $-0,12^{*}$ & 0,00 & 0,07 & 0,00 & $-0,08$ \\
\hline Convivência & $0,22 * * *$ & $-0,17 * *$ & $-0,17 * *$ & $-0,07$ & 0,09 & $0,16^{* *}$ & $-0,21 * * *$ \\
\hline Afetividade & $-0,04$ & 0,11 & $-0,03$ & 0,14 & 0,01 & 0,03 & 0,05 \\
\hline Honestidade & 0,09 & $-0,06$ & $-0,09$ & 0,02 & $-0,03$ & $0,16^{* *}$ & $-0,07$ \\
\hline Apoio social & 0,02 & 0,02 & $-0,03$ & $-0,00$ & 0,05 & $-0,13^{*}$ & 0,00 \\
\hline Realização & $-0,07$ & $0,17 * *$ & 0,08 & 0,11 & $-0,04$ & $-0,02$ & 0,07 \\
\hline Privacidade & $-0,10$ & $-0,16 * *$ & 0,11 & 0,04 & $-0,13^{*}$ & $-0,07$ & $0,14^{*}$ \\
\hline Autodireção & $-0,08$ & $0,12^{*}$ & 0,02 & $0,14^{* *}$ & 0,02 & $-0,04$ & 0,09 \\
\hline Exito & 0,04 & 0,04 & $-0,03$ & 0,04 & 0,05 & $-0,02$ & $-0,01$ \\
\hline Poder & $-0,04$ & 0,04 & 0,07 & 0,03 & 0,04 & $-0,02$ & 0,0 \\
\hline Prestígio & 0,05 & 0,00 & $-0,04$ & $-0,02$ & 0,02 & 0,10 & $-0,08$ \\
\hline Experimentação & 0,09 & 0,00 & $-0,11 *$ & 0,09 & 0,06 & 0,07 & $-0,07$ \\
\hline Estimulação & $0,17 * *$ & $-0,11 *$ & $-0,14^{*}$ & $-0,00$ & 0,08 & $0,14^{*}$ & $-0,19 * *$ \\
\hline Emoção & 0,01 & $0,12^{*}$ & 0,01 & 0,07 & 0,01 & 0,06 & 0,03 \\
\hline Sexual & $-0,03$ & 0,03 & $-0,05$ & 0,06 & $-0,00$ & $-0,01$ & $-0,01$ \\
\hline Prazer & 0,08 & $-0,04$ & $-0,05$ & 0,05 & 0,02 & 0,02 & $-0,03$ \\
\hline Suprapessoal & 0,08 & 0,01 & $-0,04$ & 0,09 & 0,04 & $-0,01$ & $-0,02$ \\
\hline Beleza & 0,08 & $-0,02$ & $-0,05$ & 0,02 & 0,07 & 0,00 & $-0,04$ \\
\hline Maturidade & 0,04 & 0,05 & $-0,04$ & 0,04 & $-0,03$ & $-0,01$ & $-0,01$ \\
\hline Conhecimento & $-0,03$ & 0,01 & 0,02 & 0,10 & $-0,04$ & 0,06 & 0,00 \\
\hline Justiça social & 0,05 & 0,02 & $-0,02$ & 0,05 & 0,08 & $-0,10$ & 0,02 \\
\hline Existência & 0,03 & 0,02 & $-0,08$ & 0,04 & 0,02 & 0,03 & $-0,06$ \\
\hline Estabilidade pessoal & $-0,07$ & 0,07 & $-0,05$ & 0,06 & $-0,02$ & $-0,03$ & 0,02 \\
\hline Sobrevivência & 0,03 & 0,01 & $-0,02$ & 0,07 & $-0,01$ & 0,03 & $-0,03$ \\
\hline Saúde & 0,09 & $-0,04$ & $-0,10$ & $-0,05$ & 0,06 & 0,07 & $-0,11$ \\
\hline
\end{tabular}

Nota: ${ }^{*} \mathrm{p}<0,05 ;{ }^{* *} \mathrm{p}<0,01, * * * \mathrm{p}<0,001$. Identificação dos indicadores de bem-estar: $\mathrm{I}=$ Afetos positivos, II $=$ Afetos negativos, III = Depressão, IV = Ansiedade, $\mathrm{V}=$ Vitalidade, $\mathrm{VI}=$ Satisfação coma vida e Total $=$ Índice geral de bem-estar subjetivo.

exatamente por estes estarem lutando pela estabilidade pessoal, o que, teoricamente, seria permitido com a titulação pretendida. Outrossim, esse resultado complementa o resultado da segunda hipótese, pois pode ser explicado pelo fato da busca incessante por essa formação superior estar comprometendo negativamente seu bem-estar, resultando assim um estado de depressão.
A quinta hipótese foi parcialmente corroborada. A função psicossocial de experimentação se correlacionou negativamente apenas com depressão $(\mathrm{r}=-0,11, \mathrm{p}$ $<0,05)$. Entre os valores específicos dessa função, estimulação apresentou correlação inversa com bem-estar $(\mathrm{r}=$ $-0,19, \mathrm{p}<0,01)$ e positiva com afetos positivos $(\mathrm{r}=0,17, \mathrm{p}$ $<0,01)$. Esse resultado parece mostrar que pelo fato de 
os professores estarem sendo obrigados a estudar em um horário especial (no sábado) para obterem uma titulação de nível superior e, conseqüentemente, se manterem no mercado de trabalho, podem estar levando a um enfrentamento de uma situação limite, acarretando assim um estado depressivo.

A sexta hipótese foi parcialmente corroborada. A função psicossocial de realização se correlacionou diretamente com os afetos negativos $(\mathrm{r}=0,17, \mathrm{p}<0,01)$, o que não era esperado. A correlação negativa mais significativa ocorreu com o valor privacidade no indicador afetos negativos $(\mathrm{r}=-0,16, \mathrm{p}<0,01)$ e diretamente no valor autodireção com ansiedade $(\mathrm{r}=0,14, \mathrm{p}<0,01)$. Esperava-se encontrar um alto índice de realização tendo em vista a busca dos professores pelo seu próprio espaço na sociedade, e de modo particular, na instituição em que atuam. Entretanto, como pode ser visto nos resultados isto não foi encontrado, supõe-se que essa busca pela formação superior de caráter obrigatório, tendo que ser realizada em pouco tempo, cause um estado de ansiedade associada a emoções negativas como preocupação.

Por fim, observa-se de um modo geral, um deterioro no bem-estar dos professores do estado da $\mathrm{Pa}$ raíba, o que pode ser analisado nos resultados das hipóteses anteriormente citadas. Nessa perspectiva, este estudo contribui com elementos que complementam as pesquisas em torno do bem-estar subjetivo e valores básicos (Chaves, 2003; Gusmão, 2004), levando em conta, nesse caso, o contexto de trabalho desses profissionais. Parece ter ficado evidente que os professores estão passando por uma espécie de pressão para poderem se manter no mercado de trabalho, o que tem trazido conseqüências quiçá danosas para seu bem-estar e que, de acordo com os valores humanos básicos por eles priorizados, estariam contribuindo igualmente para o agravamento desse quadro, isto é, as prioridades valorativas estariam sobremaneira acentuando a percepção desse bem-estar, eminentemente, subjetivo.

Esta pesquisa apresenta limitações no que diz respeito à amostra. É importante considerar outras categorias ocupacionais para comprovar esse modelo de bem-estar subjetivo utilizado, uma vez que foi comprovado apenas com a população geral em pesquisa anterior (Chaves, 2003). Sugere-se, pois, inclusive a aplicação dessa pesquisa com professores já estabilizados no mercado de trabalho, que não necessitem buscar um título para manter-se no emprego. Pode-se ainda aplicar em estudantes de pedagogia, que não estejam em regime especial, mas tão-somente enquanto estudantes. É importante considerar também em pesquisas futuras outras variáveis que possam estar ocasionando um deteri- oro no bem-estar dos professores, o que pode ser identificado através de outros estudos.

Apesar dessas limitações citadas, esta pesquisa atende aos objetivos propostos e resulta em contribuições para a psicologia, especialmente, para a psicologia educacional e organizacional e do trabalho, de modo particular, na área de saúde do trabalhador.

\section{Referências}

Brasil (1996). Lei de Diretrizes e Bases da Educação - Lei n.o 9.394/96. Brasília: Ministério da Educação. http://www.presidencia.gov.br/ccivil_03/Leis/L9394. htm

Carlotto, M. S. (2002). A síndrome de burnout e o trabalho docente. Psicologia em Estudo, 7(1), 21-29.

Chaves, S. S. S. (2003). Valores como preditores do bem-estar subjetivo (Dissertação de Mestrado). João Pessoa: Departamento de Psicologia, Universidade Federal da Paraíba.

Danna, K. \& Griffin, R. W. (1999). Health and well-being in the workplace: A review and synthesis of the literature. Journal of Management, 25(3), 357-384.

Diener, E. (2000). Subjective well-being: The science of happiness and a proposal for a national index. American Psychologist, 55(1), 34-43.

Diener, E., Emmons, R. A., Larsen, R. J. \& Griffin, S. (1985). The satisfaction with life scale. Journal of Personality Assessment, 49(1), 71-75.

Ebert, M. H., Loosen, P. T. \& Nurcombe, B. (2002). Psiquiatria: diagnóstico e tratamento. Porto Alegre: Editora Artes Médicas.

Gouveia, V. V. (1998). La naturaleza de los valores descriptores del individualismo y del colectivismo: una comparación intra e intercultural (Tese de Doutorado). Madri, Espanha. Faculdade de Psicologia, Universidade Complutense de Madri.

Gouveia, V. V. (2003). A natureza motivacional dos valores humanos: evidências acerca de uma tipologia. Estudos de Psicologia, 8(3), 431-443.

Grob, A., Little, T. D., Wanner, B. \& Wearing, A. J. (1996). Adolescents well-being and perceived control across 14 sociocultural contexts. Journal of Personality and Social Psychology, 71(4), 785-795.

Gusmão, E. E. S. (2004). A hipótese da congruência vocacional: Consideraçôes acerca dos valores humanos e do bem-estar subjetivo (Dissertação de Mestrado). João Pessoa. Departamento de Psicologia, Universidade Federal da Paraíba.

Kasser, T. \& Ahuvia, A. (2002). Materialistic values and well-being in business students. European Journal of Social Psychology, 32(1), 137-146. 
Kasser, T. \& Ryan, R. M. (1993). A dark side of the american dream: Correlates of financial success as a central life aspiration. Journal of Personality and Social Psychology, 65(2), 410-422.

Kasser, T. \& Ryan, R. M. (1996). Further examining the American dream: Differential correlates of intrinsic and extrinsic goals. Personality and Social Psychology Bulletin, 22(3), 280-287.

Lucas, R. E., Diener, E. \& Suh, E. (1996). Discriminant validity of well-being measures. Journal of Personality and Social Psychology, 71(3), 616-628.

Mariano, M. S. S. (2003). Trabalho e saúde mental das professoras da segunda fase do ensino fundamental da rede pública do município de João Pessoa - PB (Dissertação de Mestrado). João Pessoa: Departamento de Psicologia, Universidade Federal da Paraíba.

Melo, M. T. L. (1999). Programas oficiais para formação dos professores da educação básica. Educação \& Sociedade, 20(68), 45-60.

Nix, G. A., Ryan, R. M., Manly, J. B. \& Deci, E. L. (1999). Revitalization through self-regulation: The effects of autonomous and controlled motivation on happiness and vitality. Journal of Experimental Social Psychology, 35(3), 266-284.

Oishi, S., Diener, E., Lucas, R. E. \& Suh, E. (1999). Crosscultural variations in predictors of life satisfaction: Perspectives from needs and values. Personality and Social Psychology Bulletin, 25(8), 980-990.

Pasquali, L., Gouveia, V. V., Andriola, W. B., Miranda, F. J. \& Ramos, A. L. M. (1994). Questionário de Saúde Geral de Goldberg (QSG): adaptação brasileira. Psicologia: Teoria e Pesquisa, 10(3), 421-437.

Pavot, W. \& Diener, E. (1993). Review of the Satisfaction With Life Scale. Psychological Assessment, 5 (2), 164-172.

Reis, H. T., Sheldon, K. M., Gable, S. L., Roscoe, J. \& Ryan, R. M. (2000). Daily well-being: The role of autonomy, competence, and relatedness. Personality and Social Psychology Bulletin, 26(4), 419-435.

Rokeach, M. (1973). The nature of human values. New York: The Free Press.

Ryan, R. M., Chirkov, V. I., Little, T. D., Sheldon, K. M., Timoshina, E. \& Deci, E. L. (1999). The American dream in Russia: Extrinsic aspirations and well-being in two cultures. Personality and Social Psychology Bulletin, 25(12), 1509-1524.

Ryan, R. M. \& Deci, E. L. (2000). Self-determination theory and the facilitation of intrinsic motivation, social development, and well-being. American Psychologist, 55(1), 68-78.

Ryan, R. M. \& Deci, E. L. (2001). On happines and human potentials: A review of research on hedonic and eudaimonic well-being. Annual Review of Psychology, 52(1), 141-166.

Ryan, R. M. \& Frederick, C. M. (1997). On energy, personality and health: Subjective vitality as a dynamic reflection of well-being. Journal of Personality, 65(3), 259565.

Rousseau, D. M. (1997). Organizational behavior in the organizational era. Annual Review of Psychology, 48(1), 515546.

Russo, N. F. \& Dabul, A. J. (1997). The relationship of abortion to well-being. Do race and religion make a difference? Professional Psychology: Research and Practice, 28(1), 23-31.

Sauter, S. L. \& Hurrel Jr., J. J. (1999). Occupational health psychology: Origins, content, and direction. Professional Psychology: Resarch and Practice, 30(2), 123-128.

Schmutte, P. S. \& Ryff, C. D. (1997). Personality and wellbeing: Reexamining methods and meanings. Journal of Personality and Social Psychology, 73(3), 549-559.

Tróccoli, B. T. \& Salazar, A. (2003). Um estudo correlacional entre bem-estar subjetivo e estilos de coping. Trabalho apresentado no III Congresso NorteNordeste, João Pessoa, Paraíba.

Tróccoli, B. T., Salazar, A. \& Vasconcelos, T. S. (2002). Bem-estar subjetivo e o modelo dos cinco grandes fatores. Trabalho apresentado no VI Congresso Mineiro de Avaliação Psicológica, Belo Horizonte, Minas Gerais.

Recebido em maio de 2005

Reformulado em outubro de 2005 Aprovado em fevereiro de 2006

Sobre os autores:

Patrícia Nunes da Fonseca é mestra e doutoranda em Psicologia Social pela Universidade Federal da Paraíba.

Sandra Souza da Silva Chaves é mestra em Psicologia Social pela Universidade Federal da Paraíba e doutoranda em Psicologia Social e do Trabalho pela Universidade Federal do Rio Grande do Norte.

Valdiney Veloso Gouveia é doutor em Psicologia Social pela Universidade Complutense de Madrid. Professor do Programa de Pós-Graduação em Psicologia Social da Universidade Federal da Paraíba. 